\author{
Marquette University \\ e-Publications@Marquette
}

Biomedical Engineering Faculty Research and

Publications

Biomedical Engineering, Department of

$5-2012$

\title{
Within-Subject Joint Independent Component Analysis of Simultaneous fMRI/ERP in an Auditory Oddball Paradigm
}

Jain Mangalathu-Arumana

Marquette University

Scott A. Beardsley

Marquette University, scott.beardsley@marquette.edu

E. Liebenthal

Marquette University

Follow this and additional works at: https://epublications.marquette.edu/bioengin_fac

Part of the Biomedical Engineering and Bioengineering Commons

\section{Recommended Citation}

Mangalathu-Arumana, Jain; Beardsley, Scott A.; and Liebenthal, E., "Within-Subject Joint Independent Component Analysis of Simultaneous fMRI/ERP in an Auditory Oddball Paradigm" (2012). Biomedical Engineering Faculty Research and Publications. 48.

https://epublications.marquette.edu/bioengin_fac/48 


\title{
Within-Subject Joint Independent Component Analysis of Simultaneous Fmri/ERP in an Auditory Oddball Paradigm
}

\author{
J. Mangalathu-Arumana \\ Department of Biomedical Engineering, Marquette University \\ Department of Neurology, Medical College of Wisconsin \\ Milwaukee, WI \\ S. A. Beardsley \\ Department of Biomedical Engineering, Marquette University \\ Milwaukee, WI \\ Department of Biomedical Engineering, Boston University, \\ Boston, MA \\ Clinical Translational Science Institute, Medical College of \\ Wisconsin \\ Milwaukee WI \\ E. Liebenthal \\ Department of Biomedical Engineering, Marquette University \\ Department of Neurology, Medical College of Wisconsin \\ Milwaukee, WI \\ Department of Physiology, University of Manitoba \\ Winnipeg, Canada
}


NOT THE PUBLISHED VERSION; this is the author's final, peer-reviewed manuscript. The published version may be accessed by following the link in the citation at the bottom of the page.

\section{Abstract}

The integration of event-related potential (ERP) and functional magnetic resonance imaging (fMRI) can contribute to characterizing neural networks with high temporal and spatial resolution. This research aimed to determine the sensitivity and limitations of applying joint independent component analysis (jICA) within-subjects, for ERP and fMRI data collected simultaneously in a parametric auditory frequency oddball paradigm. In a group of 20 subjects, an increase in ERP peak amplitude ranging 1-8 $\mu \mathrm{V}$ in the time window of the P300 (350-700ms), and a correlated increase in fMRI signal in a network of regions including the right superior temporal and supramarginal gyri, was observed with the increase in deviant frequency difference. JICA of the same ERP and fMRI group data revealed activity in a similar network, albeit with stronger amplitude and larger extent. In addition, activity in the left pre- and post- central gyri, likely associated with right hand somato-motor response, was observed only with the jICA approach. Withinsubject, the jICA approach revealed significantly stronger and more extensive activity in the brain regions associated with the auditory P300 than the P300 linear regression analysis. The results suggest that with the incorporation of spatial and temporal information from both imaging modalities, jICA may be a more sensitive method for extracting common sources of activity between ERP and fMRI.

Keywords: fMRI, EEG, ICA, multimodal neuroimaging, auditory oddball paradigm, P300

\section{Introduction}

The advent of neuroimaging has led to major advances in understanding how the brain processes complex sensory information such as speech, and controls cognitive functions such as memory and learning. Characterizing the cortical networks involved in these processes has improved our understanding of brain function, our ability to model neural processes, and our ability to diagnose and rehabilitate patients with neurologic deficits. Unimodal, non-invasive neuroimaging techniques, such as fMRI, electroencephalography (EEG) and magnetoencephalography (MEG) are at the heart of current research in Cognitive Neuroscience. Major efforts have been directed toward optimizing the methods to temporally and spatially resolve neural activity. FMRI can be acquired in a single-slice with a temporal resolution of $100 \mathrm{~ms}$, and recent developments hold the promise for

Neurolmage, Vol. 60, No. 4 (May 2012): pg. 2247-2257. DOI. This article is (c) Elsevier and permission has been granted for this version to appear in e-Publications@Marquette. Elsevier does not grant permission for this article to be further copied/distributed or hosted elsewhere without the express permission from Elsevier. 
sub-second temporal resolution for whole brain acquisitions (Feinberg et al., 2010; Lee et al., 2010). Source reconstruction of EEG, and especially MEG, data can under ideal conditions resolve neural activity within one centimeter with high temporal resolution. Nevertheless, the slow nature of the hemodynamic response recorded in $\mathrm{FMRI}$, and the inverse problem in EEG and MEG source reconstruction, pose inherent limitations for these techniques. Therefore, an attractive alternative to unimodal neuroimaging is to fuse non-invasive imaging methodologies that together offer high spatial and high temporal resolution (Dale and Halgren, 2001). A recent development in this respect has been the integration of event-related potentials (ERPs) and functional magnetic resonance imaging (fMRI) recorded simultaneously in large-scale networks to capitalize on the high temporal resolution of ERPs and the spatially well-defined fMRI response (Bonmassar et al., 2001; Liebenthal et al., 2003).

Despite the consensus that fMRI and ERPs both reflect essentially the same type of neural activity (synaptic potentials), it is important to note that there are significant differences between the measures, which may cause discrepancies in the estimation of neural sources. In particular, brief synchronous neural activity may be captured with EEG but not with imaging of the slow BOLD response. In contrast, neural activity in a limited brain region may be visible with fMRI, but located too deep or oriented such that it does not elicit a significant ERP response (Nunez and Silberstein, 2000).

A variety of model-based methods have been developed to integrate ERP and FMRI data. Linear regression provides a well-known and robust method for multimodal integration, but it may not fully capture the richness of human brain activity. In the simplest formulation, the peak amplitude of an ERP component in an EEG timeseries is used as a regressor in the fMRI data analysis, within the framework of the general linear model (Horovitz et al., 2002; Liebenthal et al., 2003). The ERP source analysis can also be informed by spatial constraints extracted from the fMRI maps (Dale and Halgren, 2001; Esposito et al., 2009; Vanni et al., 2004).

Recently, data-driven approaches such as joint independent component analysis ( $\mathrm{jICA}$ ) have been implemented to integrate ERP and fMRI data, by searching for co-varying signals across subjects

Neurolmage, Vol. 60, No. 4 (May 2012): pg. 2247-2257. DOI. This article is (c) Elsevier and permission has been granted for this version to appear in e-Publications@Marquette. Elsevier does not grant permission for this article to be further copied/distributed or hosted elsewhere without the express permission from Elsevier. 
(Calhoun et al., 2009; Mijovic et al., 2012). The advantage of ICA, and data-driven approaches in general, lies in their ability to estimate the underlying processes when detailed á priori models are not available (Calhoun et al., 2006). JICA can recover both linear and non-linear relationships across experimental conditions and between imaging modalities. Another advantage of jICA is that it permits incorporation of multiple sources of spatial and temporal information, thereby potentially enhancing the sensitivity of the method to co-varying signals. This approach has been applied to experimental ERP and fMRI data to spatially and temporally resolve brain areas active during auditory and visual oddball detection, albeit using data from a single EEG electrode across a group of subjects (Calhoun et al., 2006; Mijovic et al., 2012). Computational simulations have suggested that jICA may be applicable to within-subject analysis, using spatial and temporal information from multi-channel EEG and spatial information from fMRI (Moosmann et al., 2008). But the potential benefits of incorporating multichannel EEG data, and its application to experimental results, have not been systematically tested.

In this study, we examined the sensitivity of jICA and the value of incorporating the full spatial and temporal array of fMRI and ERP data for resolving neural activity at a single subject level. FMRI and ERP data were acquired simultaneously during a parametric auditory oddball paradigm in twenty-four subjects. The oddball paradigm was selected because it yields extensive and robust responses in brain regions associated with sensory processing, categorization, response selection, and motor planning and execution. The P300 ERP response associated with the oddball paradigm reflects neural processes related to target detection (Coles et al., 1988; Picton, 1992; Polich, 2007; Ritter and Vaughan, 1969), and the neural generators of this response have been studied with electrophysiological methods (Basile et al., 1997; Halgren et al., 1998; Mecklinger et al., 1998; Menon et al., 1997; Smith et al., 1990) and fMRI (Friedman et al., 2009; Kiehl et al., 2005; Linden et al., 1999). Another advantage of the oddball paradigm is that it lends itself well to a parametric design. In particular, the P300 peak amplitude decreases with the increase in target detection difficulty, as indicated by decreased performance accuracy and/or increased reaction time (Polich, 2007)). In the present study, task difficulty was manipulated and a general linear model analysis of the fMRI data based on the ERP P300 peak

Neurolmage, Vol. 60, No. 4 (May 2012): pg. 2247-2257. DOI. This article is @ Elsevier and permission has been granted for this version to appear in e-Publications@Marquette. Elsevier does not grant permission for this article to be further copied/distributed or hosted elsewhere without the express permission from Elsevier. 
NOT THE PUBLISHED VERSION; this is the author's final, peer-reviewed manuscript. The published version may be accessed by following the link in the citation at the bottom of the page.

amplitude was used as a reference to compare with jICA of single subject and group data.

\section{Methods}

\subsection{Participants}

Twenty-four healthy, right-handed volunteers, ages 18-40 years, participated in the study. Participants provided written and informed consent according to the Institutional Review Boards of the Medical College of Wisconsin and Marquette University, and were compensated for their participation in the study.

Participants with no history of neurological disease and normal hearing as assessed by audiometry at $1-4 \mathrm{kHz}$ were enrolled in the study. Prior to scanning, psychometric curves were obtained for each subject based on their ability to discriminate differences in frequency (ranging from 2-40 Hz) about a $1000 \mathrm{~Hz}$ tone. A minimum discrimination accuracy of $95 \%$ at $40 \mathrm{~Hz}$ difference was required for inclusion in the study, and all participants passed this criterion. Data from four participants were subsequently excluded, two due to excessive motion during scanning, and two due to noisy EEG. The criterion for excessive motion was a rejection of more than $5 \%$ of trials due to motion in more than $5 \%$ of voxels in the dataset relative to a base functional magnetic resonance image (see image analysis below). The criterion for noisy EEG was defined as a mean baseline variance across electrodes that exceeded $10 \mu \mathrm{V}$.

\subsection{Experimental Design}

The task consisted of pressing one of two buttons to indicate whether a deviant tone was of a higher or lower frequency than the repetitive standard tones (and to guess if they could not detect the deviant). Four-tone sequences, composed of three repeated standard $1000 \mathrm{~Hz}$ tones and one deviant target tone, were presented binaurally. The tones were of $100 \mathrm{~ms}$ duration with rise/fall times of $5 \mathrm{~ms}$, and were presented at $800 \mathrm{~ms}$ stimulus onset asynchrony. The frequency deviant was inserted in position 3 or 4 in the sequence. The deviant tone was chosen from one of ten possible frequencies, five lower and

Neurolmage, Vol. 60, No. 4 (May 2012): pg. 2247-2257. DOI. This article is (c) Elsevier and permission has been granted for this version to appear in e-Publications@Marquette. Elsevier does not grant permission for this article to be further copied/distributed or hosted elsewhere without the express permission from Elsevier. 
five higher than the standard tone frequency, corresponding to five levels of task difficulty. The deviant frequencies were individually tailored based on a least-square error Weilbull fit to each participant's psychometric curve, such that levels 1-5 corresponded to frequency differences that resulted in 50,65, 75, 85, and 95\% accuracy in the prescan test. One hundred and forty four trials were presented at each of the five levels, for a total of 720 trials, broken into twelve separate runs, acquired in two recording sessions on separate days. The onset of each auditory sequence was jittered relative to the time of image acquisition, such that the deviant tone was always presented $4000 \mathrm{~ms}$ before the middle of the next image acquisition block, and the image acquisition coincided with the estimated peak of the BOLD response (Hall et al., 1999). Auditory stimuli were delivered using a pneumatic, MRI-compatible headphone system (Avotec, Inc., Stuart, FL), and the sequence of stimulus presentation was controlled with the Presentation software (Neurobehavioral Systems Inc., San Pablo, CA).

\subsection{Data Acquisition}

The study was conducted on a GE 3T Signa Excite scanner (GE Health Care, Milwaukee, WI). Functional MR images consisted of $\mathrm{T}_{2}{ }^{*}$ weighted, gradient-echo, echo planar images acquired using a clustered volume acquisition ( $\mathrm{TE}=25 \mathrm{~ms}$; flip angle $=77^{\circ} ; \mathrm{TR}=7 \mathrm{~s}$; slices $=33)$, with a five second silent interval. Axially-oriented contiguous slices $(3 \times 3 \times 3.5 \mathrm{~mm}$ voxels) covering the entire brain were acquired (image acquisition=2.0s). High-resolution anatomical images of the entire brain were also acquired using a 3D spoiled gradient-echo (SPGR) sequence $(0.9 \times 0.9 \times 1 \mathrm{~mm}$ voxels $)$. EEG was recorded continuously using an MRI-compatible MagLink system consisting of a 64-channel MagLink cap (62 monopolar electrodes, and 2 bipolar leads for ECG and VEOG), SynAmps amplifier, and a Scan 4.4 Workstation (Compumedics Neuroscan, Inc., TX). Sintered Ag/Ag-Cl electrodes were positioned according to the extended International 10-20 system, with a hard-wired reference located at CPZ. EEG was recorded at $500 \mathrm{~Hz}$.

Neurolmage, Vol. 60, No. 4 (May 2012): pg. 2247-2257. DOI. This article is (c) Elsevier and permission has been granted for this version to appear in e-Publications@Marquette. Elsevier does not grant permission for this article to be further copied/distributed or hosted elsewhere without the express permission from Elsevier. 
NOT THE PUBLISHED VERSION; this is the author's final, peer-reviewed manuscript. The published version may be accessed by following the link in the citation at the bottom of the page.

\subsection{FMRI linear regression analysis}

Functional MR image analysis was performed using the AFNI software package (Cox, 1996). The raw fMRI data were unpacked and the 2D image slices were converted into 3D datasets. For each subject the functional images were volumetrically registered to a base image (image 3 in run 1), which was acquired close in time to the anatomical images and after the BOLD signal had stabilized. Deconvolution was then performed to extract task-relevant BOLD activity. A reference function coding the peak amplitude of the trial-averaged P300 ERP component in each task level was used as an individual regressor to estimate the hemodynamic response at each voxel. Translation and rotation motion parameters estimated during registration were used as noise covariates in the regression. Anatomical images were transformed into Talairach-Tournoux coordinates (Tournoux, 1988) to spatially normalize data between subjects. The functional images were transformed into Talaraich-Tournoux coordinates using the aligned anatomical images as a template volume. The individual functional maps were smoothed with a $6 \mathrm{~mm}$ full width half maximum gaussian filter, and the group results were computed using a random effects voxel-wise t-test against zero. The output dataset was thresholded at a voxel-wise threshold of $p<0.05$, and clusters larger than $882 \mu$ l were removed to obtain a map-wise threshold of $\alpha<0.05$. The corrected cluster threshold was estimated with Monte-Carlo simulation using the AFNI alphasim module (Cox, 1996).

\subsection{EEG preprocessing}

EEG analysis was performed using the Scan 4.4 Edit module (Compumedics Neuroscan Inc., TX). Channels showing a variance $>20$ $\mu \mathrm{V}$ during the baseline period ( -200 to $-50 \mathrm{~ms}$ ) were removed from further analysis. The average number of channels excluded per subject was seven. EEG data were first filtered using a $0.1-30 \mathrm{~Hz}$ zero-phase bandpass FIR filter with a $48 \mathrm{~dB}$ /octave roll-off. Signals were then corrected to remove the ballistocardiogarm artifact (BA) introduced by the MR environment. With the clustered MR image acquisition design for simultaneous fMRI/EEG (Liebenthal et al., 2003), removal of gradient artifacts in the EEG is not necessary because the EEG epochs used to compute ERPs are not contaminated.

Neurolmage, Vol. 60, No. 4 (May 2012): pg. 2247-2257. DOI. This article is @ Elsevier and permission has been granted for this version to appear in e-Publications@Marquette. Elsevier does not grant permission for this article to be further copied/distributed or hosted elsewhere without the express permission from Elsevier 
ERPs were computed using an epoch time from $-200 \mathrm{~ms}$ to 800 ms relative to deviant onset. Epochs were baseline adjusted to compensate for drifts that occurred during EEG acquisition. Epochs in which the signal exceeded $\pm 200 \mu \mathrm{V}$ were deemed to contain artifacts and were discarded. The average number of accepted trials per subject and per condition was $86 \%$. ERP waveforms were digitally rereferenced to the mastoid electrodes. In the group analyses, the grand average ERP waveform in each condition was computed by averaging the ERPs across subjects.

\subsection{Joint Independent Component Analysis (JICA)}

The full spatial and temporal array of fMRI and ERP data was integrated here using a within-subject variation of the group jICA approach described by Calhoun et al. (Calhoun et al., 2010; Calhoun et al., 2006; Edwards et al., 2011). For jICA within-subject (Figure 1), the fMRI data was restructured into a NxM matrix where each row corresponded to the flattened image volume obtained for a single experimental condition relative to task level 1(task difficulty level, $\mathrm{N}=4$ ). The ERP data was restructured into an NxP matrix with each row containing the flattened spatiotemporal sequence of data across electrodes for a single task condition. The fMRI and ERP data sets were then concatenated into a single row to create a joint-matrix encompassing the full data set obtained across experimental conditions and imaging modalities. Principal Component Analysis (PCA) was applied to the joint-matrix to whiten the signal, but the dimension of the dataset was not reduced. JICA was performed on the PCA extracted components, utilizing the jICA toolbox (Matlab, gift toolbox, 2.0b). The resulting jICA components consisted of a spatial jICA-fMRI map and a spatiotemporal jICA-ERP map. The jICA-fMRI map was thresholded at $p<0.05$ (voxelwise, as determined from the distribution of all jICA-fMRI components). A corrected map-wise threshold of $a<0.05$ was applied, relative to chance distribution computed by randomizing the jICA-fMRI voxel values of all four components. JICA components whose fMRI signal survived this threshold, and their corresponding jICA-ERP components, were selected for further analysis.

Neurolmage, Vol. 60, No. 4 (May 2012): pg. 2247-2257. DOI. This article is (c) Elsevier and permission has been granted for this version to appear in e-Publications@Marquette. Elsevier does not grant permission for this article to be further copied/distributed or hosted elsewhere without the express permission from Elsevier. 
NOT THE PUBLISHED VERSION; this is the author's final, peer-reviewed manuscript. The published version may be accessed by following the link in the citation at the bottom of the page.

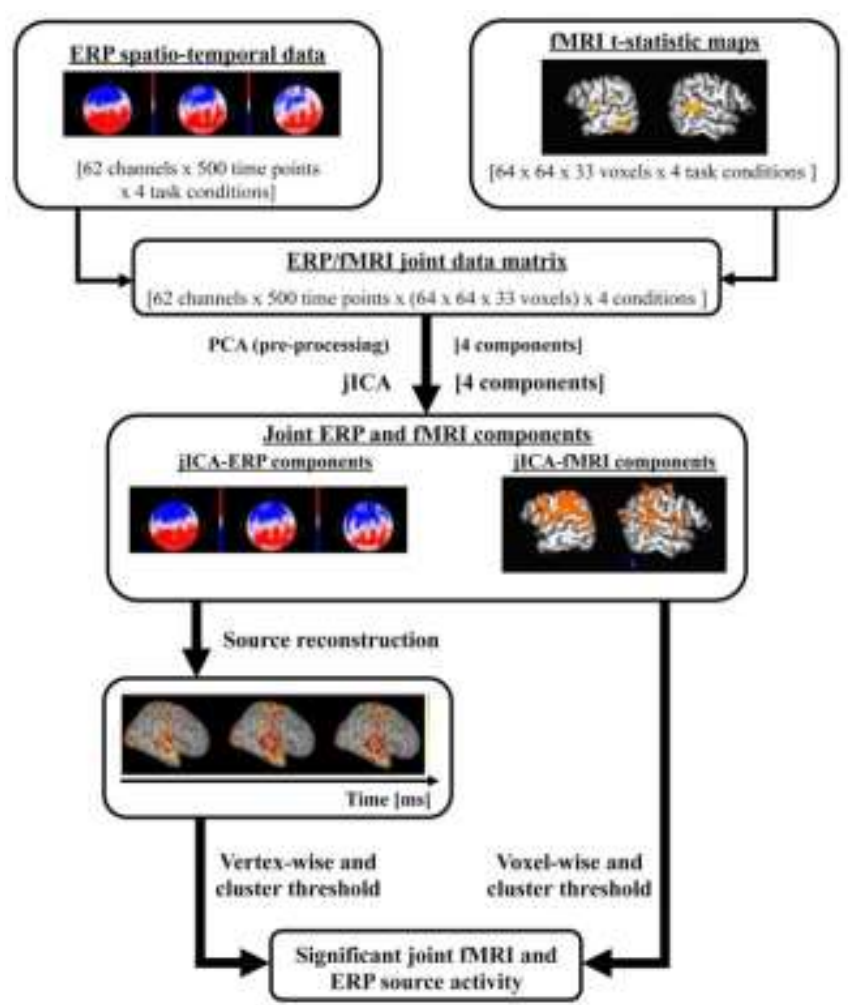

\section{Figure 1}

Schematic of within-subject jICA across task levels. The EEG data is first concatenated across time points, electrodes and conditions. In the case of the fMRI, voxels are concatenated across conditions. EEG and fMRI datasets are concatenated into a single joint data matrix. PCA is applied as a pre-processing step to whiten the data and jICA was applied to the whitened joint data matrix. Source localization of the jICA-ERP components was used to reconstruct the spatial distribution of source activity across the cortical surface. JICA-fMRI components were voxel-wise and cluster thresholded and jICA-ERP components were vertex-wise and cluster thresholded to identify components with significant joint fMRI and ERP source activity.

In the group analysis, the jICA-fMRI map was created by computing the $t$-value of the mean of twenty components that survived significance against zero. The t-test map was thresholded voxelwise at $p<0.05$ and a corrected map-wise threshold of $a<0.05$ was applied. The jICA-ERP map consisted of the mean of the twenty jICA-ERP components that survived significance.

In a subsequent analysis, jICA was also applied to a single EEG electrode $(\mathrm{Pz})$ and the entire $\mathrm{FMRI}$ data set, to compare against the full spatiotemporal jICA in which all sixty-two EEG channels were used. The statistical analyses of the jICA components were the same as

Neurolmage, Vol. 60, No. 4 (May 2012): pg. 2247-2257. DOI. This article is @ Elsevier and permission has been granted for this version to appear in e-Publications@Marquette. Elsevier does not grant permission for this article to be further copied/distributed or hosted elsewhere without the express permission from Elsevier. 
NOT THE PUBLISHED VERSION; this is the author's final, peer-reviewed manuscript. The published version may be accessed by following the link in the citation at the bottom of the page.

those described above. This analysis was performed to investigate the sensitivity of jICA when more spatiotemporal information is included.

\subsection{Source Reconstruction}

Within-subject source reconstruction of ERP data and jICA-ERP components was performed using the weighted minimum norm estimate (WMNE) to solve the inverse problem (Brainstorm 3.0, Matlab 2010b). The head was modeled in BrainVISA (v. 4.1.1) using the subject's high-resolution T1-weighted MR images, and a 3-shell sphere Berg approximation representing the brain, scalp, and skull with conductivities of $0.33,0.0042$, and 0.33 respectively. The cortical surface was parsed and represented as a high-density mesh of vertices and subsequently down-sampled to 15,000 vertices (in Matlab). Sample electric dipoles were positioned at each vertex, with their directions constrained to be perpendicular to the cortical surface. Electrode positions on the scalp were determined manually based on the EEG gel artifact observed in the MR images.

Source reconstruction of the group (grand average) ERP and jICA-ERP waveforms was similarly computed, using high-resolution T1 weighted MR images of the template Colin brain to create a head model in Freesurfer ( $v$ 5.0). Electrode positions were approximated based on a template electrode position file.

Current source density estimates were z-score normalized relative to the baseline ( -200 to $-50 \mathrm{~ms}$ prior to deviant onset). Each source map was thresholded vertex-wise at $p<0.05$ relative to the post-stimulus distribution of all vertices across time, and a clusterthreshold (five vertices connected) was applied.

\subsection{Region of Interest analysis}

The source density profiles of the ERP and jICA-ERP data in several regions of interest (ROI) were examined in order to characterize the temporal dynamics of task-related neural sources. ROIs were determined functionally from the fMRI P300 linear regression group maps, and constrained using anatomical definitions from the TT_N27 atlas in Afni (in Talairach space). Four ROIs were

Neurolmage, Vol. 60, No. 4 (May 2012): pg. 2247-2257. DOI. This article is (c) Elsevier and permission has been granted for this version to appear in e-Publications@Marquette. Elsevier does not grant permission for this article to be further copied/distributed or hosted elsewhere without the express permission from Elsevier. 
selected, in the right and left posterior superior temporal gyrus (STG) and in the right and left supramarginal gyrus (SMG). These regions were selected for analysis, because they are commonly activated in auditory oddball paradigms (Polich, 2007), including in the present study. A brain surface model was created from the Colin brain available in Brainstorm (projected into Talairach space), and reconstructed in Freesurfer ( $v 5.0$ ). The four ROIs were projected onto the Colin surface model, and discontinuities in region boundaries were smoothed using a two-vertex region growing algorithm, followed by a two-vertex region reduction to maintain the approximate surface area of each original ROI. For the ROI analysis, the source maps of subject 4138 were also projected to the Brainstorm Colin brain, so that the same ROIs could be applied to both the group and single subject results.

For each ROI, the signal-to-noise ratio (SNR) and the number of vertices that survived a vertex-wise significance threshold of $p<0.05$ relative to the distribution of all vertices across the post-stimulus time interval (0-800 ms) were computed. SNR was computed over time as the difference between the mean current density across ROI vertices with significant activity $(p<0.05)$ in the post-stimulus period and the mean current density across the cortical surface in the baseline period, divided by the variance of the baseline source activity. Vertices in the baseline period were selected randomly with the constraint that the overall number of vertices matched that of the activated vertices within the ROI. Subsequently, the area under the SNR curve was computed for the N100 window, from 50-200 ms, and for the P300 window from 350-700 ms.

\section{Results}

\subsection{Psychometric curves}

The psychometric curve for tone discrimination in a representative subject (4138) is shown in Figure 2 (left panel). In this subject, accuracy varied from 22 to $100 \%$ for frequency differences of 2 and $40 \mathrm{~Hz}$, respectively, and generally increased with frequency difference. A least-square Weilbull fit was used to determine the five task levels for the scanner study, corresponding to prescan accuracies

Neurolmage, Vol. 60, No. 4 (May 2012): pg. 2247-2257. DOI. This article is (c) Elsevier and permission has been granted for this version to appear in e-Publications@Marquette. Elsevier does not grant permission for this article to be further copied/distributed or hosted elsewhere without the express permission from Elsevier. 
of $50,65,75,85$ and $95 \%$. The tone discrimination performance of subject 4138 during the $\mathrm{FMRI} / \mathrm{ERP}$ study and the range of performance across the group of twenty participants are shown in Figure 2B.

A.

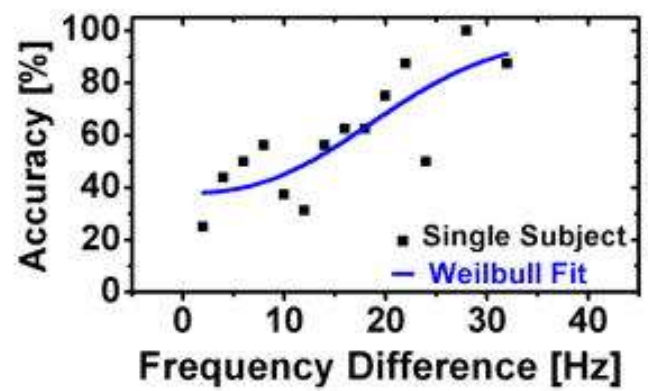

B.

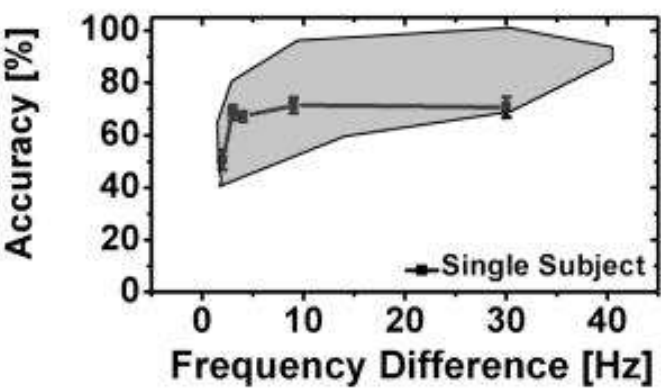

\section{Figure 2}

(A) Prescan tone discrimination performance on the oddball task and least-square error Weibull fit to the psychometric curve for subject 4138. (B) Tone discrimination accuracy ( \pm 1 S.E.) for subject 4138 in the fMRI/ERP session at five deviant levels corresponding to 50,65, 75, 85 and $95 \%$ prescan accuracy (black line). The grayed region shows the range in performance accuracy across 20 subjects.

\subsection{ERP Waveforms}

The subject 4138 (A) and grand average (B) ERP waveforms at electrode $\mathrm{Pz}$ are shown in Figure 3 for the five task-difficulty levels. The insets show the scalp topography of the ERP component at the positive peak of the response to the level five frequency difference (420 ms for subject 4138 and $430 \mathrm{~ms}$ for the grand average). For both the single subject and the grand average, the amplitude of the component peaking around $430 \mathrm{~ms}$ increased with task level, and its topography was parietal, consistent with the P300 (Polich, 2007). The mean (across subjects) peak amplitude of the P300 as a function of task level is shown in Figure 3C. The mean (across subject) reaction time as a function of P300 peak amplitude is shown in Figure 3D. It is noteworthy that the P300 peak response as a function of task level was modeled more accurately as nonlinear (2-parameter exponential) than linear $\left(r^{2}=0.98\right.$ and 0.75 , respectively). Similarly, the reaction time as a function P300 amplitude was also modeled more accurately as nonlinear than linear $\left(r^{2}=0.96\right.$ and 0.86 , respectively).

Neurolmage, Vol. 60, No. 4 (May 2012): pg. 2247-2257. DOI. This article is (C) Elsevier and permission has been granted for this version to appear in e-Publications@Marquette. Elsevier does not grant permission for this article to be further copied/distributed or hosted elsewhere without the express permission from Elsevier. 
A.

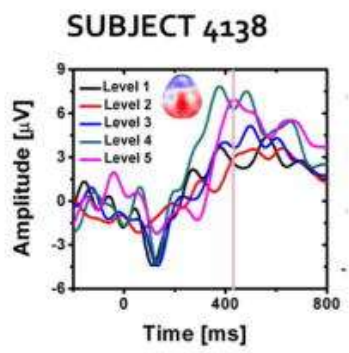

B. GROUP $(\mathrm{N}=20)$

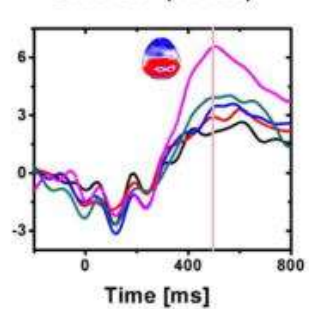

C.

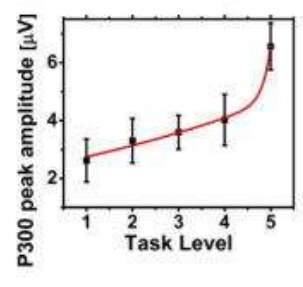

D.

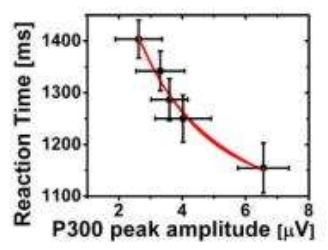

Figure 3

ERP responses at electrode $\mathrm{Pz}$ to five deviant frequency levels corresponding to 50$95 \%$ prescan performance accuracy for (A) subject 4138 and (B) the group. (C) Group mean P300 peak amplitude at electrode Pz as a function of task level and (D) task reaction time as a function of $\mathrm{P} 300$ peak amplitude. Plots in $C$ and $D$ are fit with a twoparameter exponential curve (red trace). Error bars denote standard error across subjects.

\subsection{FMRI Linear Regression Maps}

The group fMRI linear regression map obtained using the individual level-wise P300 peak amplitudes for within-subject analysis is shown in Figure 4A. The primary areas activated in this map were the right middle and posterior portions of the superior temporal gyrus (STG), the left middle STG, the left inferior temporal gyrus (ITG), and the left inferior frontal gyrus (IFG). Results for the P300 linear regression in subject 4138 are shown in Figure 4B. This map showed small regions of positive activation in the middle and posterior STG and supramarginal gyrus (SMG), bilaterally. Supplementary Tables 1 and 2 list the peak coordinates and extent of the significant clusters of activation found in the fMRI regression maps for the group of twenty subjects and for subject 4138 , respectively. The size of significant clusters in the linear regression analysis ranged $1103-22,704 \mu \mathrm{l}$ in the group map (with two large clusters corresponding to activity in the left inferior parietal lobule, and right superior parietal lobule) and 1-379 $\mu$ l for subject 4138.

Neurolmage, Vol. 60, No. 4 (May 2012): pg. 2247-2257. DOI. This article is @ Elsevier and permission has been granted for this version to appear in e-Publications@Marquette. Elsevier does not grant permission for this article to be further copied/distributed or hosted elsewhere without the express permission from Elsevier. 
A.

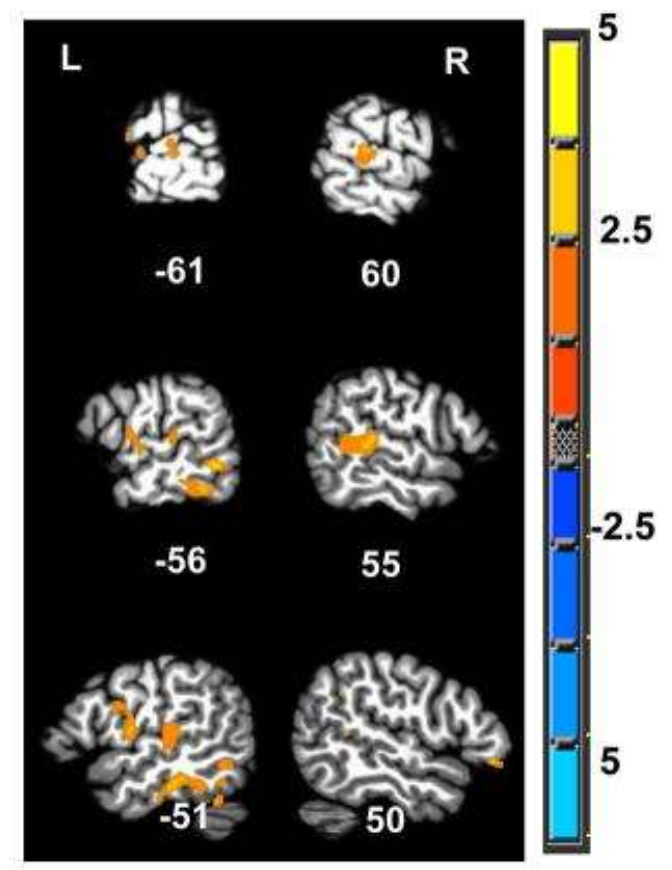

\section{t-value}

B.

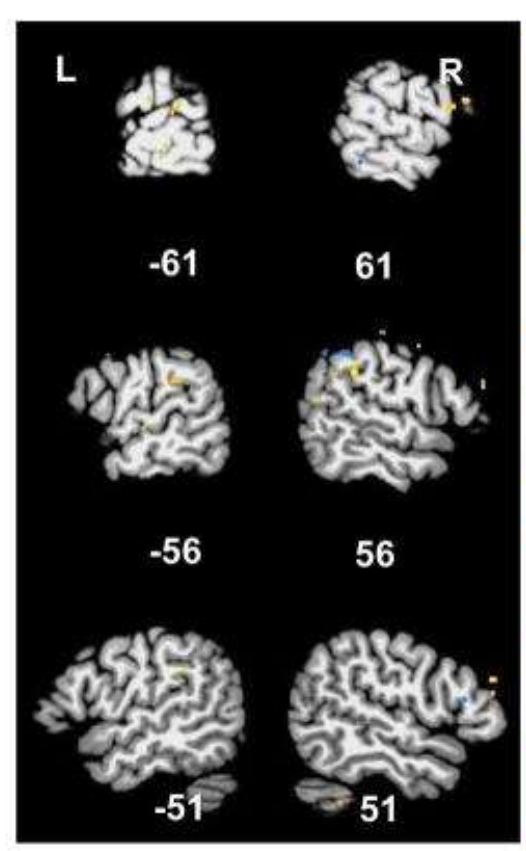

t-value

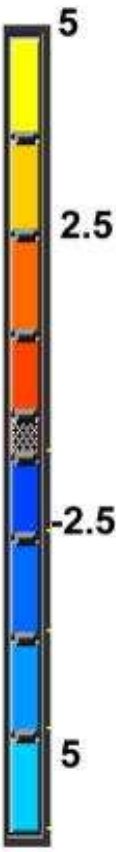

\section{Figure 4}

FMRI activity using the P300 peak amplitude as a regressor $(A)$ in a group of 20 subjects ( $\alpha<0.05$, corrected for multiple comparisons), and (B) in subject 4138 $(p<0.05$, uncorrected), overlaid on a template brain in Talairach space (TT_N27 Colin brain). Slice numbers, indicating the distance (in $\mathrm{mm}$ ) in the sagittal plane from the origin in the anterior commissure are shown. L-left; R-right.

\subsection{Source Reconstruction of the P300 ERP component}

Source reconstructions of the group P300 ERP response for task level 5 are shown in Figure 5 . Task level 5 was selected for the source reconstruction because the P300 amplitude was largest at this level. Source reconstruction of the group activity revealed sources in the time window of the P300 in the right superior temporal plane and gyrus (STP/STG), right supramarginal gyrus (SMG) and right middle frontal gyrus (MFG). On the left, sources were observed in the preand post- central gyri (PreCG and PostCG, respectively), IFG, posterior STG, and occipital cortex. The single subject source reconstructions (not shown) were generally noisy, with sources observed in multiple brain regions and at additional time points outside the N100 and P300 time windows. This result is likely related to the low SNR of the ERPs 
in a single subject (SNR $\approx 2$ ) compared to the grand average ERPs $(\mathrm{SNR} \approx 5)$.

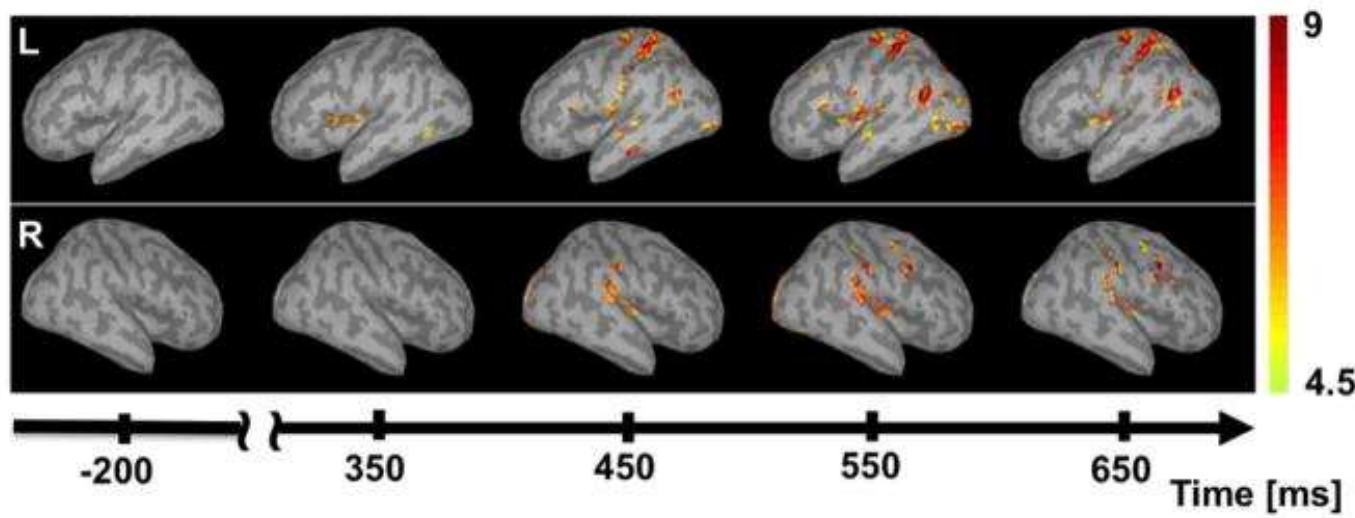

\section{Figure 5}

Source reconstruction for the grand average $(\mathrm{N}=20)$ level 5 ERP in the baseline period prior to deviant onset ( -200 to $0 \mathrm{~ms}$ ), and at $100 \mathrm{~ms}$ intervals during the P300 response ( 350 to $650 \mathrm{~ms}$ ), in the left (L) and in the right (R) hemispheres. Source magnitude is expressed as a $z$-score relative to the magnitude during the baseline period.

\section{5 jICA-fMRI maps}

JICA was applied on the ERP and fMRI data across task levels. Only one jICA-fMRI-ERP component in each subject survived the significance threshold, and therefore a total of twenty components were used in the group analysis. The group jICA-fMRI map (Figure 6A) revealed activity in the middle and posterior STG and in the SMG, bilaterally, as well as in the PreCG, PostCG and IFG, predominantly on the left. Clusters in this analysis ranged 412-25,055 $\mu$ l (with one large cluster corresponding to activity in the left postcentral gyrus). This pattern of activity was similar to that observed in the group P300 linear regression map (Figure 4A) in the superior temporal and frontal cortex. However, the activity returned by jICA was stronger (approximately $50 \%$ increase in t-value in the right middle and posterior STG and SMG, and in the left PreCG and PostCG) and more extensive, as evident from comparison of cluster sizes between the two maps (see table 3 in the supplement). Other important differences were that activity in the PreCG and PostCG, consistent with the P300 source reconstruction maps (Figures 5 and 8 ), was observed only in 
NOT THE PUBLISHED VERSION; this is the author's final, peer-reviewed manuscript. The published version may be accessed by following the link in the citation at the bottom of the page.

the jICA-fMRI maps. In contrast, activity in the right ITG was observed only in the $\mathrm{P} 300$ regression maps.

A.

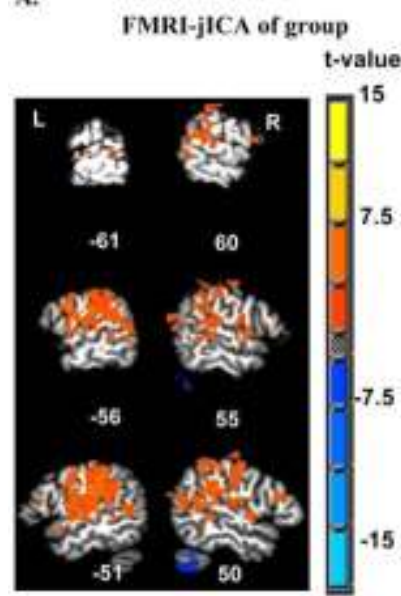

FMRI-JICA of subject 4138

$$
\text { ICA-Ampl. }
$$

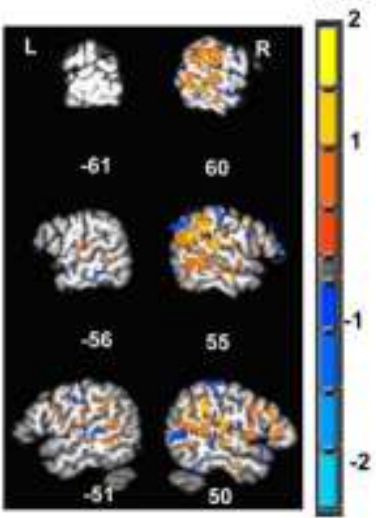

\section{Figure 6}

FMRI jICA for $(A)$ the group of twenty subjects (t-test of twenty components against zero), and for (B) subject 4138 (both at $a<0.05$, corrected for multiple comparisons), overlaid on the T_N27 Colin brain. Slice numbers are indicated.

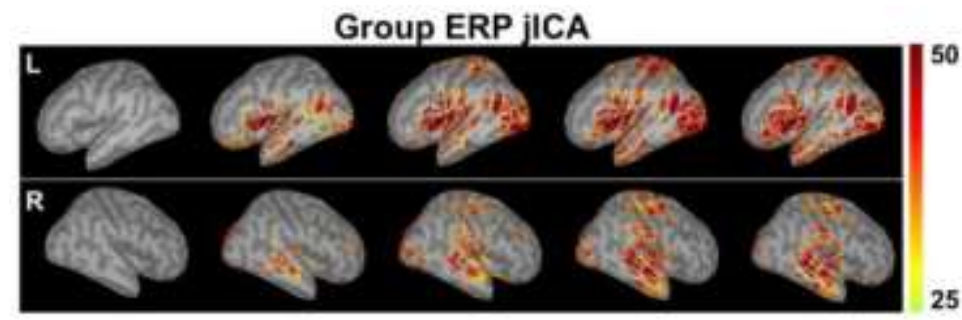

Subject 4138 ERP jICA

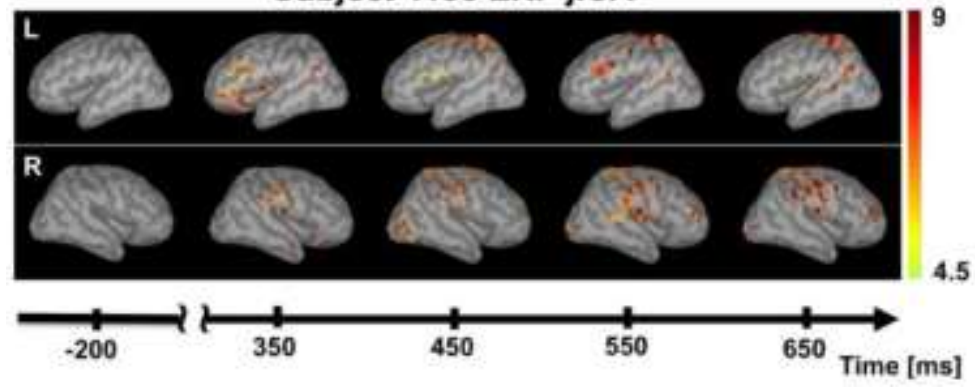

\section{Figure 8}

Time series of the ERP jICA source reconstruction in the baseline interval ( -200 to 0 $\mathrm{ms}$ ), and at $100 \mathrm{~ms}$ intervals during the P300 response (350 to $650 \mathrm{~ms}$ ), for the group (top) and for subject 4138 (bottom), in the right (R) and left (L) hemispheres. Source magnitude is expressed as a $\mathrm{z}$-score relative to the magnitude during the baseline period.

Neurolmage, Vol. 60, No. 4 (May 2012): pg. 2247-2257. DOI. This article is @ Elsevier and permission has been granted for this version to appear in e-Publications@Marquette. Elsevier does not grant permission for this article to be further copied/distributed or hosted elsewhere without the express permission from Elsevier. 
The jICA-fMRI map for subject 4138 (Figure 6B) showed strong activity in the middle and posterior STG and in the SMG, predominantly on the right, as well as in PreCG, PostCG, and IFG bilaterally (clusters ranged $189-2142 \mu \mathrm{l}$; see table 4 in the supplement). The single subject jICA map revealed activity in the same network of regions as the group jICA map. However, the pattern of lateralization of the individual and group maps was somewhat different. The differences in lateralization may reflect individual differences, which result in more bilateral activity at the group level. The single subject jICA results were far more robust than those for the single subject P300 linear regression, as evidenced by the strong similarity of the individual jICA (but not P300 regression) map to the group maps.

\section{6 jICA-ERP}

The jICA-ERP waveforms at electrode Pz for the group of twenty subjects (blue) and for subject 4138 (red) are shown in Figure 7. The group and single subject waveforms overlap closely, both showing a marked increase in amplitude during the P300 time window (as observed in the group and individual ERP waveforms shown in Figure 3 ). There is also a negative phase peaking around $140 \mathrm{~ms}$ and corresponding to the N100 time window. However, the peak amplitudes in the negative and positive phases of the ERP are larger, and the negativity is more distinct, in the single subject jICA results. These differences may be due to smoothing in the group ERPs due to inter-individual differences in the latency of the N100 and P300 components.

Neurolmage, Vol. 60, No. 4 (May 2012): pg. 2247-2257. DOI. This article is (C Elsevier and permission has been granted for this version to appear in e-Publications@Marquette. Elsevier does not grant permission for this article to be further copied/distributed or hosted elsewhere without the express permission from Elsevier. 


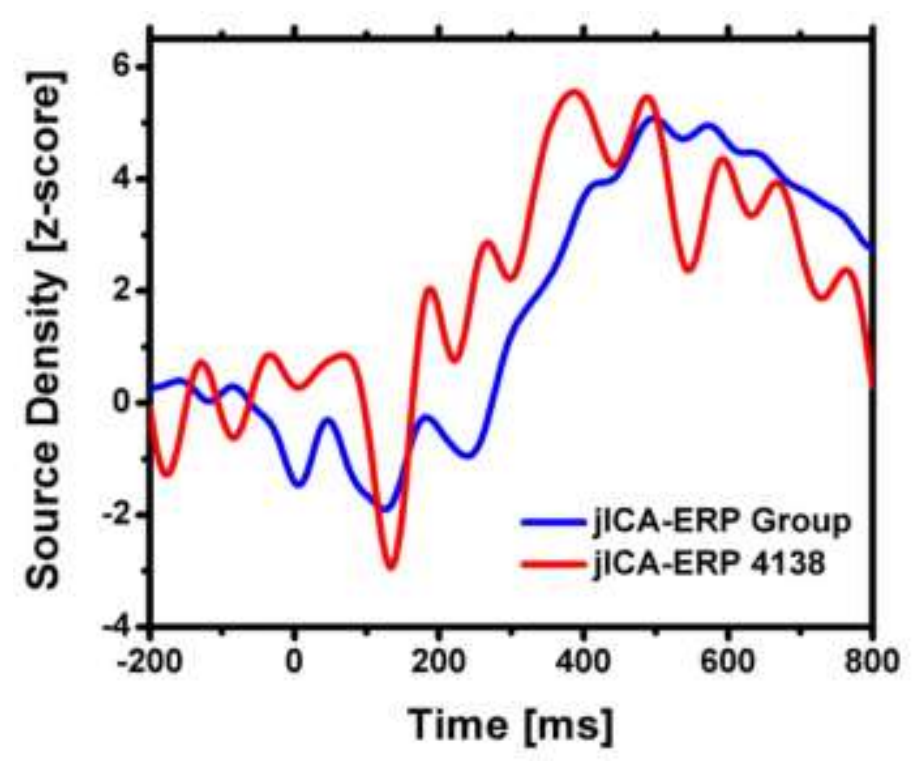

Figure 7

ERP jICA at electrode Pz for the group of twenty subjects (blue) and subject 4138 (red).

\subsection{Source Reconstruction of the jICA-ERP}

Source reconstructions of the jICA-ERP data, for the group of subjects and for subject 4138, are shown in Figure 8 . Source magnitudes are reported as a z-score computed relative to the baseline interval ( -200 to $-50 \mathrm{~ms}$ ). The group source reconstruction (top panel) showed significant P300 related activity in the STP, STG, and SMG, bilaterally, with a slightly larger extent on the right. Activity was also observed in the IFG, PreCG and PostCG, and occipital cortex, bilaterally, but with larger extent on the left. These results were similar to those of the group ERP source reconstructions and the group jICA-fMRI map. In subject 4138 (bottom panel), activity was observed in the same network of regions, albeit with smaller z-scores, likely due to the lower SNR at the individual level.

\subsection{Region of interest analysis}

Figure 9 shows the mean time course of statistically significant vertices $(p<0.05)$ in four task-relevant ROIs (left and right STG and SMG), for sources reconstructed from jICA (solid line) and task level 5 (dashed line) activity, in the group (top panel), and in subject 4138 
(bottom panel). This measure roughly reflects the extent of activation within each ROI as a function of time. At the group level (top panel), the jICA sources contained more statistically significant vertices than the level 5 sources in all ROIs, specifically in the N100 (STG ROIs) and P300 (all ROIs) time windows. In subject 4138, the number of significant vertices was generally smaller in the jICA than level 5 sources (except in the right SMG). However, the temporal profiles of the jICA sources in the individual data were better defined in that they showed increases relative to baseline specifically during the time windows of the N100 and P300.

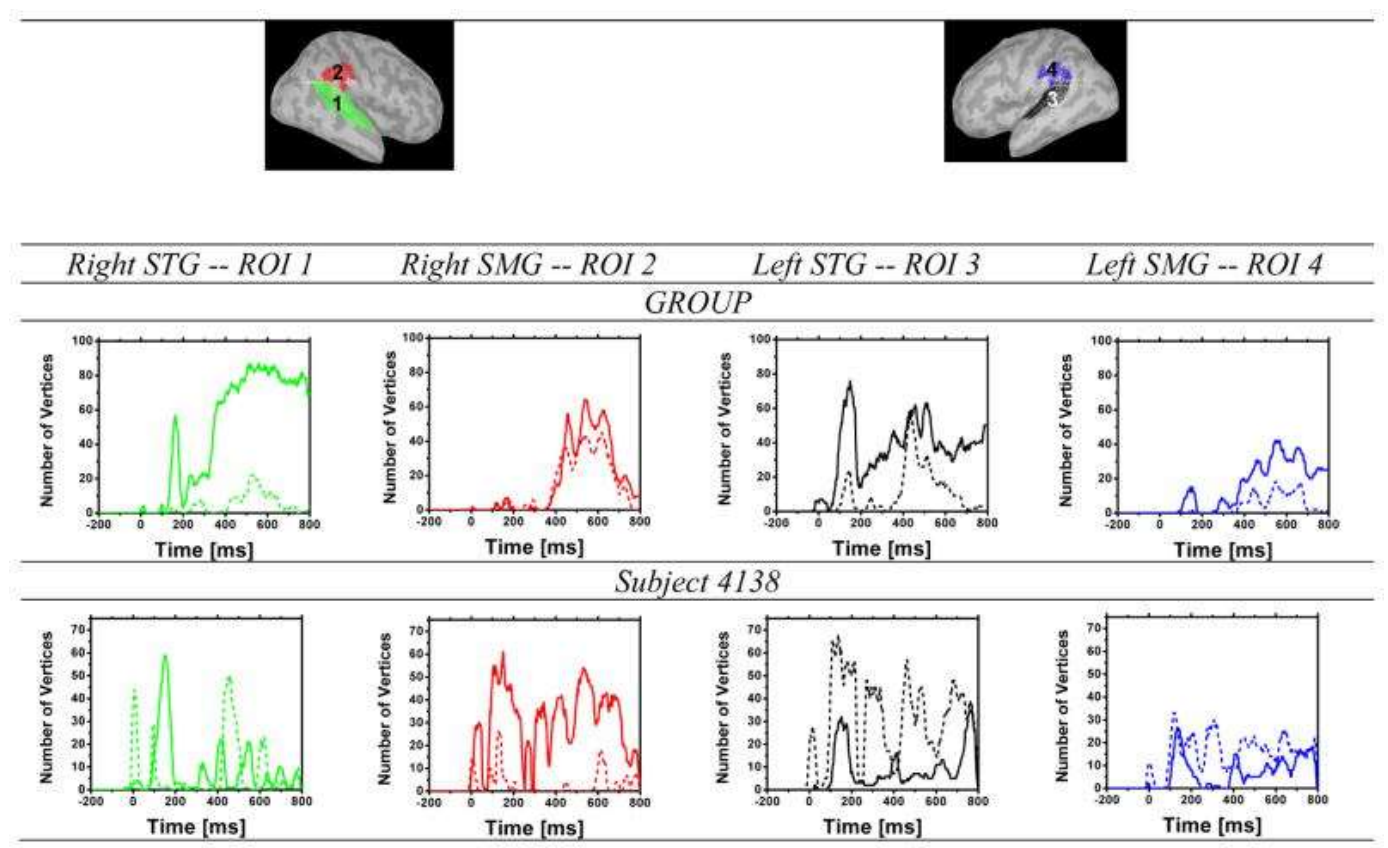

\section{Figure 9}

Number of vertices within each ROI with significant ERP activity $(p<0.05)$, for jICA exctracted across task levels (solid line), and for level 5 (dotted line), as a function of time relative to deviant onset at $0 \mathrm{~ms}$. Results are shown separately for the group (top) and for subject 4138 (bottom)in the left and right SMG (red and blue, respectively) and the left and right STG (green and black, respectively).

Figure 10 shows the time course of the SNR in the same four ROIs for the group data (top panel) and for subject 4138 (bottom panel). The area under the SNR curve is reported in Table 1 , for the N100 peak from 50-200 ms, and for the P300 peak from 350 to 700 ms. In the group data, the jICA relative to level 5 SNR showed a $20 \%$ increase in the right STG, and a 70\% increase in the right SMG, in the area under the curve measured from 350 to $700 \mathrm{~ms}$,. In subject 4138, 
the jICA relative to level 5 SNR showed a 300\% increase in the right SMG in the area under the SNR curve, measured from 350 to $700 \mathrm{~ms}$. The single subject temporal profiles were generally consistent with those of the group and those reported in the literature for auditory oddball detection, revealing a progression of neural activity from STG to SMG associated with the N100 and P300 responses. Differences in the activation pattern between the single subject and group data may reflect individual variations in the location and lateralization of temporoparietal activity related to auditory oddball detection, and/or deviations in the positioning of ROIs and source localization relative to individual neuroanatomy.

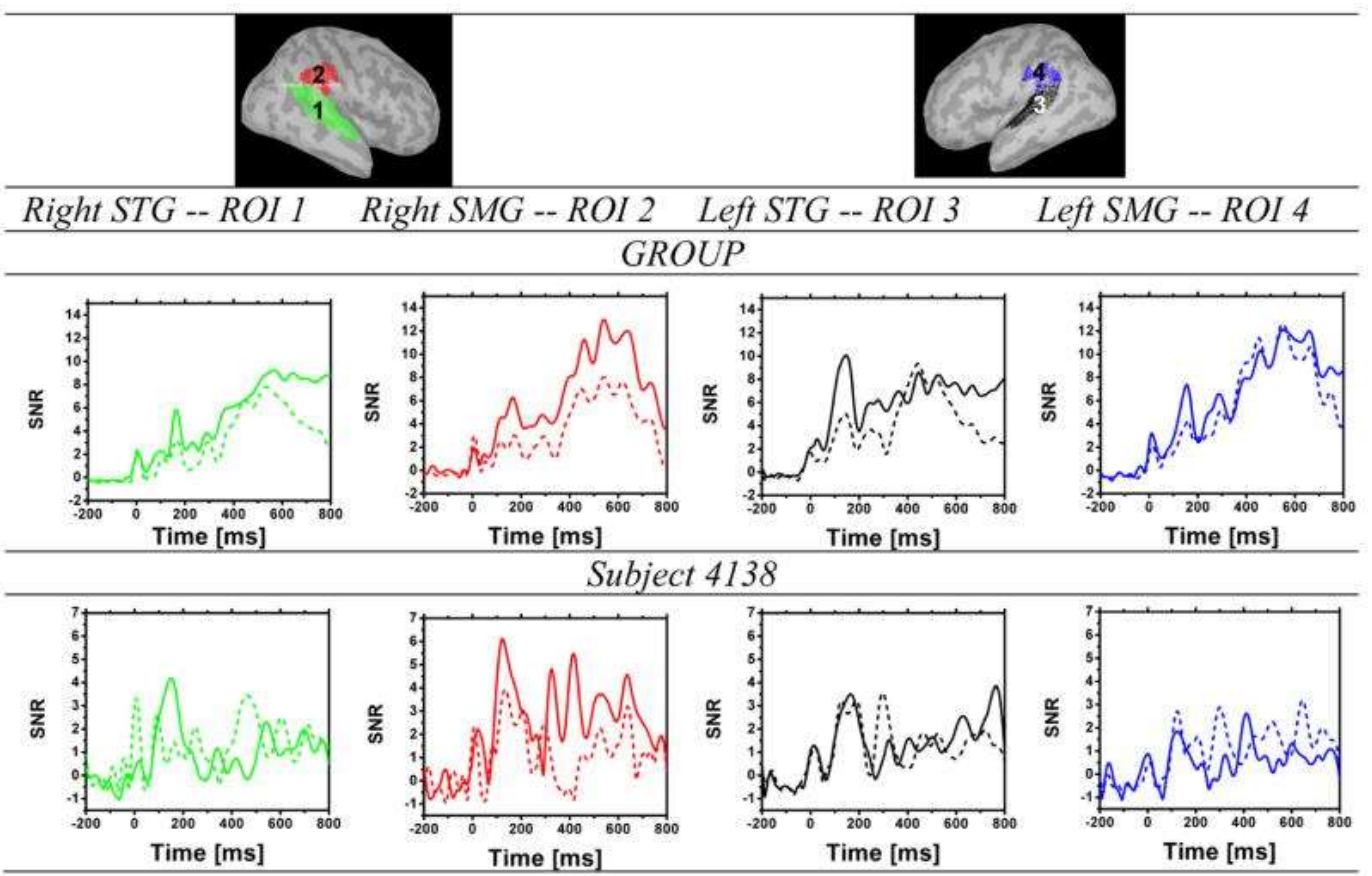

Figure 10

SNR is shown for the group (top) and for subject 4138 (bottom) ERP jICA extracted across task levels (solid line) and ERP activity in level 5 (dotted line), as a function of time relative to deviant onset at $0 \mathrm{~ms}$, in the left and right SMG (red and blue, respectively)and the left and right STG (green and black, respectively).

Neurolmage, Vol. 60, No. 4 (May 2012): pg. 2247-2257. DOI. This article is @ Elsevier and permission has been granted for this version to appear in e-Publications@Marquette. Elsevier does not grant permission for this article to be further copied/distributed or hosted elsewhere without the express permission from Elsevier. 
NOT THE PUBLISHED VERSION; this is the author's final, peer-reviewed manuscript. The published version may be accessed by following the link in the citation at the bottom of the page.

\begin{tabular}{|c|c|c|c|c|c|c|c|c|}
\hline \multirow[b]{2}{*}{ Group } & \multicolumn{2}{|c|}{ STG R } & \multicolumn{2}{|c|}{ SMG R } & \multicolumn{2}{|l|}{ STG L } & \multicolumn{2}{|c|}{ SMG L } \\
\hline & N100 & P300 & N100 & P300 & N100 & P300 & N100 & P30C \\
\hline Level 5 & 225 & 2071 & 268 & 2097 & 464 & 2216 & 366 & 3458 \\
\hline jICA & 430 & 2725 & 592 & 3485 & 982 & 2549 & 594 & 3477 \\
\hline \multicolumn{9}{|c|}{ Subject 4138} \\
\hline Level 5 & 164 & 615 & 328 & 365 & 305 & 410 & 172 & 528 \\
\hline jICA & 377 & 339 & 543 & 1146 & 307 & 520 & 117 & 309 \\
\hline
\end{tabular}

\section{Table 1}

Area under the curve (representing SNR) of the level 5 and jICA N100 and P300 components, in the four ROIs, for the group and for subject 4138 . The N100 interval was selected from 50-200 ms and the P300 interval from 350-700 ms.

\subsection{Multi-Channel versus Single-Channel jICA-ERP}

In order to investigate whether the sensitivity of jICA for extracting common fMRI and ERP sources is increased when multiple ERP channels are included, jICA was compared between two data sets. One set included all sixty-two ERP channels and the entire fMRI volume (described above), and the other contained only one ERP channel $(\mathrm{Pz})$ and the entire fMRI volume. A voxelwise t-test showing the differences between the resulting jICA-fMRI maps is shown in Figure 11 . The difference map shows that jICA, with the full array of spatiotemporal information, yielded significantly more activity in regions specifically associated with the P300, including the STG bilaterally and the right SMG. With the exception of activity immediately below the Pz electrode, there were no areas that showed stronger activity for the single ERP channel analysis. The results suggest that there is an advantage to using the full array of ERP electrodes in jICA.

Neurolmage, Vol. 60, No. 4 (May 2012): pg. 2247-2257. DOI. This article is @ Elsevier and permission has been granted for this version to appear in e-Publications@Marquette. Elsevier does not grant permission for this article to be further copied/distributed or hosted elsewhere without the express permission from Elsevier. 


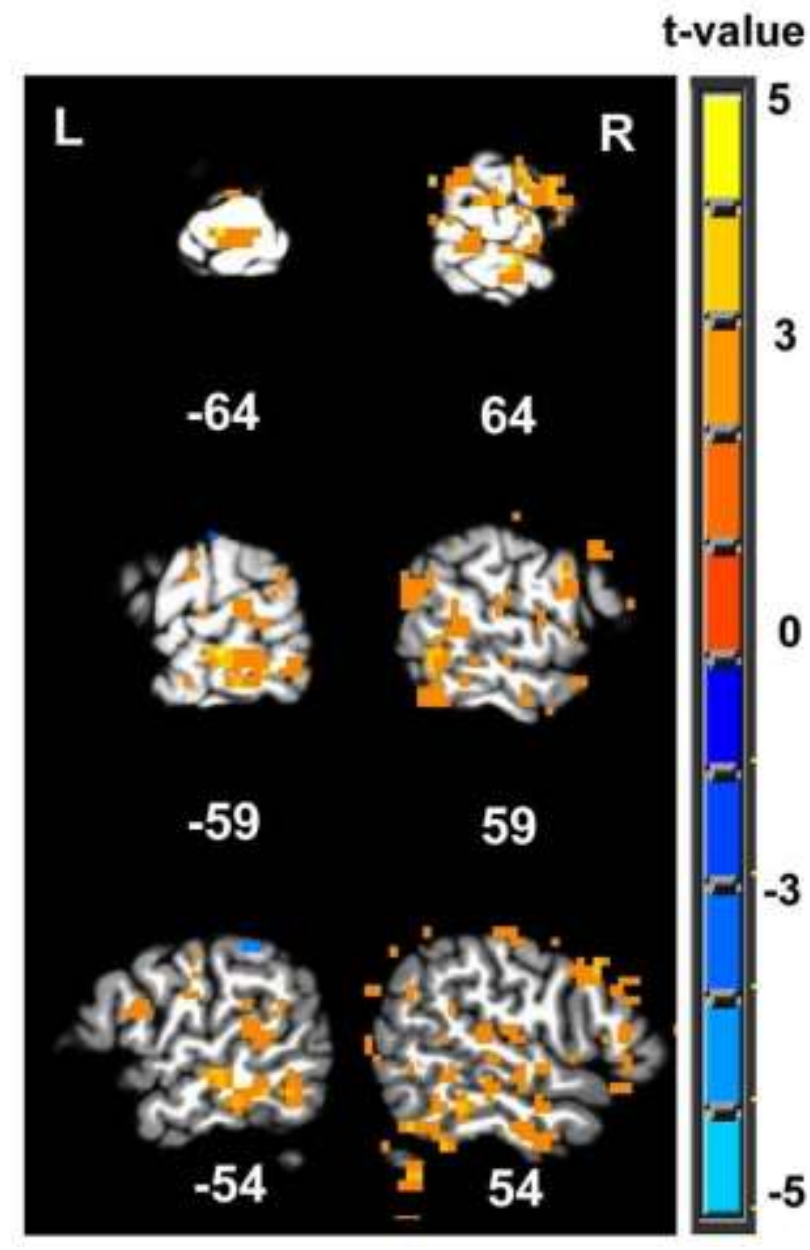

\section{Figure 11}

T-test between the jICA fMRI group maps obtained using the full spatiotemporal sequence of multi-channel EEG activity, and using a single electrode, Pz.

\section{Discussion}

The integration of neural activity recorded simultaneously with EEG and fMRI can highlight the temporal dynamics of different brain regions. The integration of ERP and fMRI within-subject could be useful for the diagnosis of neuropathology. This paper compared jICA, fully integrating parametric fMRI and ERP P300 data, to using the P300 ERP peak amplitude as a regressor in a general linear model. The jICA approach depicts both linear and non-linear covariations between the EEG and fMRI signals and is therefore more comprehensive than the general linear regression model. In addition, jICA utilized the full array of ERP electrodes and ERP data points, as opposed to the single 
electrode and point in time (peak activity) used (here and typically) in the linear regression analysis, thereby potentially allowing for more sensitive characterization of neural activity.

The group and single subject jICA-fMRI results revealed activity in the superior temporal and supramarginal cortex, predominantly on the right. These areas have been associated with auditory processing and auditory oddball detection in previous work (Linden, 2005; Linden et al., 1999) and in the P300 linear regression performed here. Activity was also observed in the precentral and postcentral gyri, predominantly on the left, likely reflecting right-hand motor planning and motor control. This latter finding is consistent with the strong relationship between mean motor response time and mean P300 peak amplitude observed here (Figure 3D), and with previous work suggesting involvement of this region in motor response during an oddball task (Linden et al., 1999; Strobel et al., 2008).

The source reconstruction of the jICA-ERP group data revealed activity during the P300 time window in the superior temporal and supramarginal gyri, bilaterally, and in the occipital, inferior frontal, and pre- and post- central gyri, predominantly on the left. These source maps are generally consistent with previous reports of the P300 neural sources showing involvement of a posterior temporal, parietal and frontal network, bilaterally, in auditory target detection (Halgren et al., 1980; Linden, 2005). Activity in the middle portion of the superior temporal plane and gyrus observed in the present study may be associated with automatic auditory oddball detection and the mismatch negativity (MMN) component, which varies with deviant size similarly to the P300 (Liebenthal et al., 2003; Opitz et al., 1999). Whether neural generators in the hippocampi contribute to the $\mathrm{P} 300$ remains controversial (Basile et al., 1997; Halgren et al., 1980; Polich and Squire, 1993). The present study cannot shed light on this issue because only cortical sources were modeled in the source reconstruction.

The jICA source reconstruction maps were also largely consistent with the source reconstruction maps of the group ERP data, and the group fMRI maps. However, activity in the left occipital cortex was observed only in the ERP source reconstructions and not in the fMRI maps. Activation of the occipital cortex has been reported in

Neurolmage, Vol. 60, No. 4 (May 2012): pg. 2247-2257. DOI. This article is @ Elsevier and permission has been granted for this version to appear in e-Publications@Marquette. Elsevier does not grant permission for this article to be further copied/distributed or hosted elsewhere without the express permission from Elsevier. 
previous EEG source reconstructions of the auditory P300 (Anderer et al., 1998; Volpe et al., 2007), and also in simultaneous EEG/fMRI studies using a trial-by-trial analysis (Benar et al., 2007; Goldman et al., 2009). Although the role of this region in auditory target detection remains uncertain, a tentative conclusion emerging from previous work is that activity in the lateral occipital cortex is modulated by momentary fluctuations in a general attention network, which may be captured better with EEG.

A primary difference between the fMRI P300 linear regression and jICA maps was that only the jICA maps showed activity in the precentral and postcentral gyri. This result may be related to the fact that mean response times did not vary linearly with the mean P300 peak amplitude (Figure 3D), and were therefore not well modeled in the P300 linear regression. Another difference between the fMRI maps was that the main areas associated with the P300, namely the right superior temporal and supramarginal gyri, were activated more strongly and extensively with the jICA approach (Supplement tables $1-4)$. This difference may again be related to the fact that the P300 ERP peak amplitude did not vary perfectly linearly with task level (Figure 3C), such that co-variations between the ERP and fMRI data were better modeled with the jICA approach.

A general drawback of the general linear model (GLM) is that assumptions about the co-linearity of the ERP and fMRI data may not always hold, for example at low levels of sensory stimulation (Logothetis et al., 2001), or in pathological conditions such as stroke, Alzheimer's or Parkinson's disease (Girouard and Iadecola, 2006; Polich and Corey-Bloom, 2005; Polich and Pitzer, 1999). In such cases, jICA could provide a more sensitive approach for ERP and fMRI data fusion because the method is applicable to both linear and nonlinear relationships.

In this work, the full array of spatial and temporal information from the ERPs was incorporated into the jICA approach. In contrast, the P300 linear regression used information from only one electrode at the time point of the P300 peak amplitude. The superior sensitivity of jICA relative to the GLM may largely be related to these factors. The importance of including additional ERP channels is supported by the comparison of the single and multi-channel jICA-ERP. Our comparison

Neurolmage, Vol. 60, No. 4 (May 2012): pg. 2247-2257. DOI. This article is @ Elsevier and permission has been granted for this version to appear in e-Publications@Marquette. Elsevier does not grant permission for this article to be further copied/distributed or hosted elsewhere without the express permission from Elsevier. 
showed that with one electrode, the sensitivity of jICA to P300 related activity in the right superior temporal and supramarginal gyri was significantly reduced. Taken together, the results suggest that incorporating more spatiotemporal information is useful for fusing EEG with $\mathrm{fMRI}$. The benefits from incorporating more spatiotemporal information from the ERP waveform will be investigated in computational modeling studies aimed at further optimization of jICA for EEG-fMRI data fusion.

Perhaps the most significant finding of this study is that the approach proposed here, using jICA to fully integrate fMRI and ERP data in the context of a parametric paradigm, lends itself well to within-subject analysis. The single subject jICA-fMRI data and source reconstruction of the jICA-ERP component were both consistent with the group jICA maps. In contrast, the individual fMRI P300 regression maps and ERP source reconstructions were generally too noisy to evaluate. Specifically, SNR comparisons in the representative subject data revealed a mean increase of $25 \%$ in the jICA-ERP relative to the ERP in regions associated with $\mathrm{N} 100$ and P300 activity (Table 1), and a mean increase of approximately seven fold in the number of active voxels in the jICA-fMRI maps relative to the linear regression fMRI maps (Supplement, Tables 4 and 2). The positive performance of jICA with individual data is particularly important because it sets the stage for implementation of multimodal neuroimaging as a clinically relevant diagnostic tool.

A few other studies have reported data-driven approaches for EEG-fMRI data fusion at a single subject level, primarily using a trial by trial design (Brown et al., 2010; Debener et al., 2005; MartinezMontes et al., 2004; Yang et al., 2010). Different from these studies, here a single jICA-fMRI component survived the significance threshold in each subject. This result may be related to the relatively low variability in the current data set, in which jICA was applied to extract ERP-fMRI activation covarying across five experimental conditions (with one serving as a baseline). Higher variability in the data set can be achieved, for example in a trial-by-trial jICA approach, albeit at the cost of lower SNR. Another distinction of the jICA approach is the use of a common mixing matrix for the ERP and fMRI data. Compared to other approaches using a separate mixing matrix (Brown et al., 2010; Correa et al., 2008), jICA may be particularly sensitive to highly

Neurolmage, Vol. 60, No. 4 (May 2012): pg. 2247-2257. DOI. This article is @ Elsevier and permission has been granted for this version to appear in e-Publications@Marquette. Elsevier does not grant permission for this article to be further copied/distributed or hosted elsewhere without the express permission from Elsevier. 
correlated or highly uncorrelated neural activity between the imaging modalities (Correa et al., 2008), but the performance of this method with partially correlated sources remains to be determined. Future work using computational simulations, could provide further insight into optimal designs for separating specific neural sources into different components.

In summary, the jICA approach used here, incorporating spatiotemporal information from both fMRI and ERP data in the context of a parametric auditory oddball paradigm, yielded stronger and more extensive activity in brain regions associated with the auditory P300 compared to a P300 peak amplitude linear regression analysis. The benefit of the jICA approach was observed at the level of group and in single subject analyses, making this method amenable to the development of clinical applications. The results suggest that with incorporation of the full set of spatial and temporal information from both imaging modalities, jICA may be a more sensitive method to extract common sources between ERPs and fMRI. 
NOT THE PUBLISHED VERSION; this is the author's final, peer-reviewed manuscript. The published version may be accessed by following the link in the citation at the bottom of the page.

\section{Supplementary Material}

\begin{tabular}{|c|c|c|c|c|c|c|c|}
\hline Volume & Mean & Max & $x$ & $y$ & $\mathbf{z}$ & Lobe & Structure \\
\hline \multicolumn{8}{|c|}{ Positive activations } \\
\hline 1612 & 2.32 & 2.98 & 60 & -27 & 10 & Right Temporal & Superior Temporal Gyrus \\
\hline 13523 & 2.32 & 3.62 & 20 & -81 & 36 & Right Parietal & Superior Parietal Lobule \\
\hline 1788 & 2.46 & 4.27 & 39 & 38 & -4 & Right Frontal & Middle Frontal Gyrus \\
\hline 1173 & 2.29 & 3.00 & 29 & 17 & -4 & Right & Insula \\
\hline 3327 & 2.48 & 4.42 & -48 & -23 & -18 & \multirow[t]{4}{*}{ Left Temporal } & Inferior Temporal Gyrus \\
\hline 1301 & 2.35 & 2.98 & -25 & -76 & -14 & & Fusiform Gyrus \\
\hline 1297 & 2.22 & 2.59 & -48 & -24 & 13 & & Superior Temporal Gyrus \\
\hline 1103 & 2.39 & 3.39 & -41 & -56 & 4 & & Middle Temporal Gyrus \\
\hline 22704 & 2.34 & 4.03 & -29 & -77 & 42 & Left Parietal & Inferior Parietal Lobule \\
\hline 4045 & 2.26 & 2.98 & -10 & -8 & 51 & \multirow[t]{3}{*}{ Left Frontal } & Frontal Gyrus \\
\hline 2482 & 2.54 & 4.39 & -26 & 53 & 8 & & Middle Frontal Gyrus \\
\hline 1109 & 2.27 & 2.89 & -50 & -5 & 11 & & Inferior Frontal Gyrus \\
\hline 2330 & 2.39 & 3.61 & -1 & -55 & \begin{tabular}{|l|}
-23 \\
\end{tabular} & Left Cerebellum & Cerebellum \\
\hline
\end{tabular}

\section{Acknowledgments}

The authors would like to thank Anjali Desai for her help with the EEG data collection, and Dr. Tom Prieto and Tim Thelaner for their help running the EEG hardware. This research was supported by the National Institutes Health NIDCD R01 DC006287 (to E. L.), and the Falk Family Medical Research Trust.

\section{Footnotes}

Publisher's Disclaimer: This is a PDF file of an unedited manuscript that has been accepted for publication. As a service to our customers we are providing this early version of the manuscript. The manuscript will undergo copyediting, typesetting, and review of the resulting proof before it is 
NOT THE PUBLISHED VERSION; this is the author's final, peer-reviewed manuscript. The published version may be accessed by following the link in the citation at the bottom of the page.

published in its final citable form. Please note that during the production process errors may be discovered which could affect the content, and all legal disclaimers that apply to the journal pertain.

\section{References}

1. Anderer P, Pascual-Marqui RD, Semlitsch HV, Saletu B. Differential effects of normal aging on sources of standard N1, target N1 and target P300 auditory event-related brain potentials revealed by low resolution electromagnetic tomography (LORETA) Electroencephalogr Clin Neurophysiol. 1998;108:160-174.

2. Basile LF, Rogers RL, Simos PG, Papanicolaou AC. Magnetoencephalographic evidence for common sources of long latency fields to rare target and rare novel visual stimuli. Int J Psychophysiol. 1997;25:123-137.

3. Benar CG, Schon D, Grimault S, Nazarian B, Burle B, Roth M, Badier JM, Marquis $\mathrm{P}$, Liegeois-Chauvel $\mathrm{C}$, Anton JL. Single-trial analysis of oddball event-related potentials in simultaneous EEG-fMRI. Hum Brain Mapp. 2007;28:602-613.

4. Bonmassar G, Schwartz DP, Liu AK, Kwong KK, Dale AM, Belliveau JW. Spatiotemporal brain imaging of visual-evoked activity using interleaved EEG and fMRI recordings. Neuroimage. 2001;13:10351043.

5. Brown KS, Ortigue S, Grafton ST, Carlson JM. Improving human brain mapping via joint inversion of brain electrodynamics and the BOLD signal. Neuroimage. 2010;49:2401-2415.

6. Calhoun V, Wu L, Kiehl K, Eichele T, Pearlson G. Aberrant Processing of Deviant Stimuli in Schizophrenia Revealed by Fusion of FMRI and EEG Data. Acta Neuropsychiatr. 2010;22:127-138.

7. Calhoun VD, Adali T, Pearlson GD, Kiehl KA. Neuronal chronometry of target detection: fusion of hemodynamic and event-related potential data. Neuroimage. 2006;30:544-553.

8. Calhoun VD, Liu J, Adali T. A review of group ICA for fMRI data and ICA for joint inference of imaging, genetic, and ERP data. Neuroimage. 2009;45:S163-172.

Neurolmage, Vol. 60, No. 4 (May 2012): pg. 2247-2257. DOI. This article is (c) Elsevier and permission has been granted for this version to appear in e-Publications@Marquette. Elsevier does not grant permission for this article to be further copied/distributed or hosted elsewhere without the express permission from Elsevier. 
NOT THE PUBLISHED VERSION; this is the author's final, peer-reviewed manuscript. The published version may be accessed by following the link in the citation at the bottom of the page.

9. Coles MG, Gratton G, Donchin E. Detecting early communication: using measures of movement-related potentials to illuminate human information processing. Biol Psychol. 1988;26:69-89.

10. Correa NM, Li YO, Adali T, Calhoun VD. Canonical Correlation Analysis for Feature-Based Fusion of Biomedical Imaging Modalities and Its Application to Detection of Associative Networks in Schizophrenia. IEEE J Sel Top Signal Process. 2008;2:998-1007.

11. Cox RW. AFNI: software for analysis and visualization of functional magnetic resonance neuroimages. Comput Biomed Res. 1996;29:162173.

12. Dale AM, Halgren E. Spatiotemporal mapping of brain activity by integration of multiple imaging modalities. Curr Opin Neurobiol. 2001;11:202-208.

13. Debener S, Ullsperger M, Siegel M, Fiehler K, von Cramon DY, Engel AK. Trial-by-trial coupling of concurrent electroencephalogram and functional magnetic resonance imaging identifies the dynamics of performance monitoring. J Neurosci. 2005;25:11730-11737.

14. Edwards BG, Calhoun VD, Kiehl KA. Joint ICA of ERP and fMRI during error-monitoring. Neuroimage 2011

15. Esposito F, Mulert C, Goebel R. Combined distributed source and singletrial EEG-fMRI modeling: application to effortful decision making processes. Neuroimage. 2009;47:112-121.

16. Feinberg DA, Moeller S, Smith SM, Auerbach E, Ramanna S, Gunther M, Glasser MF, Miller KL, Ugurbil K, Yacoub E. Multiplexed echo planar imaging for sub-second whole brain FMRI and fast diffusion imaging. PLoS One. 2010;5:e15710.

17. Friedman D, Goldman R, Stern Y, Brown TR. The brain's orienting response: An event-related functional magnetic resonance imaging investigation. Hum Brain Mapp. 2009;30:1144-1154.

18. Girouard H, Iadecola $\mathrm{C}$. Neurovascular coupling in the normal brain and in hypertension, stroke, and Alzheimer disease. J Appl Physiol. 2006;100:328-335.

Neurolmage, Vol. 60, No. 4 (May 2012): pg. 2247-2257. DOI. This article is @ Elsevier and permission has been granted for this version to appear in e-Publications@Marquette. Elsevier does not grant permission for this article to be further copied/distributed or hosted elsewhere without the express permission from Elsevier 
19. Goldman RI, Wei CY, Philiastides MG, Gerson AD, Friedman D, Brown TR, Sajda $P$. Single-trial discrimination for integrating simultaneous EEG and fMRI: identifying cortical areas contributing to trial-to-trial variability in the auditory oddball task. Neuroimage. 2009;47:136147.

20. Halgren E, Marinkovic K, Chauvel P. Generators of the late cognitive potentials in auditory and visual oddball tasks. Electroencephalogr Clin Neurophysiol. 1998;106:156-164.

21. Halgren E, Squires NK, Wilson CL, Rohrbaugh JW, Babb TL, Crandall PH. Endogenous potentials generated in the human hippocampal formation and amygdala by infrequent events. Science. 1980;210:803-805.

22. Hall DA, Haggard MP, Akeroyd MA, Palmer AR, Summerfield AQ, Elliott MR, Gurney EM, Bowtell RW. "Sparse" temporal sampling in auditory fMRI. Hum Brain Mapp. 1999;7:213-223.

23. Horovitz SG, Skudlarski P, Gore JC. Correlations and dissociations between BOLD signal and P300 amplitude in an auditory oddball task: a parametric approach to combining fMRI and ERP. Magn Reson Imaging. 2002;20:319-325.

24. Kiehl KA, Stevens MC, Laurens KR, Pearlson G, Calhoun VD, Liddle PF. An adaptive reflexive processing model of neurocognitive function: supporting evidence from a large scale $(n=100)$ fMRI study of an auditory oddball task. Neuroimage. 2005;25:899-915.

25. Lee K, Tak S, Ye JC. A data-driven sparse GLM for fMRI analysis using sparse dictionary learning with MDL criterion. IEEE Trans Med Imaging. 2010;30:1076-1089.

26. Liebenthal E, Ellingson ML, Spanaki MV, Prieto TE, Ropella KM, Binder JR. Simultaneous ERP and fMRI of the auditory cortex in a passive oddball paradigm. Neuroimage. 2003;19:1395-1404.

27. Linden DE. The p300: where in the brain is it produced and what does it tell us? Neuroscientist. 2005;11:563-576.

28. Linden DE, Prvulovic D, Formisano E, Vollinger M, Zanella FE, Goebel R, Dierks $T$. The functional neuroanatomy of target detection: an fMRI study of visual and auditory oddball tasks. Cereb Cortex. 1999;9:815823.

Neurolmage, Vol. 60, No. 4 (May 2012): pg. 2247-2257. DOI. This article is @ Elsevier and permission has been granted for this version to appear in e-Publications@Marquette. Elsevier does not grant permission for this article to be further copied/distributed or hosted elsewhere without the express permission from Elsevier. 
NOT THE PUBLISHED VERSION; this is the author's final, peer-reviewed manuscript. The published version may be accessed by following the link in the citation at the bottom of the page.

29. Logothetis NK, Pauls J, Augath M, Trinath T, Oeltermann A. Neurophysiological investigation of the basis of the fMRI signal. Nature. 2001;412:150-157.

30. Martinez-Montes E, Valdes-Sosa PA, Miwakeichi F, Goldman RI, Cohen MS. Concurrent EEG/fMRI analysis by multiway Partial Least Squares. Neuroimage. 2004;22:1023-1034.

31. Mecklinger A, Maess B, Opitz B, Pfeifer E, Cheyne D, Weinberg H. A MEG analysis of the P300 in visual discrimination tasks. Electroencephalogr Clin Neurophysiol. 1998;108:45-56.

32. Menon V, Ford JM, Lim KO, Glover GH, Pfefferbaum A. Combined eventrelated fMRI and EEG evidence for temporal-parietal cortex activation during target detection. Neuroreport. 1997;8:3029-3037.

33. Mijovic B, Vanderperren $K$, Novitskiy $N$, Vanrumste $B$, Stiers $P$, Van den Bergh B, Lagae L, Sunaert S, Wagemans J, Van Huffel S, De Vos M. The "why" and "how" of JointICA: Results from a visual detection task. Neuroimage 2012.

34. Moosmann M, Eichele T, Nordby H, Hugdahl K, Calhoun VD. Joint independent component analysis for simultaneous EEG-fMRI: principle and simulation. Int J Psychophysiol. 2008;67:212-221.

35. Nunez PL, Silberstein RB. On the relationship of synaptic activity to macroscopic measurements: does co-registration of EEG with fMRI make sense? Brain Topogr. 2000;13:79-96.

36. Opitz B, Mecklinger A, Von Cramon DY, Kruggel F. Combining electrophysiological and hemodynamic measures of the auditory oddball. Psychophysiology. 1999;36:142-147.

37. Picton TW. The P300 wave of the human event-related potential. J Clin Neurophysiol. 1992;9:456-479.

38. Polich J. Updating P300: an integrative theory of P3a and P3b. Clin Neurophysiol. 2007;118:2128-2148.

39. Polich J, Corey-Bloom J. Alzheimer's disease and P300: review and evaluation of task and modality. Curr Alzheimer Res. 2005;2:515-525.

Neurolmage, Vol. 60, No. 4 (May 2012): pg. 2247-2257. DOI. This article is (c Elsevier and permission has been granted for this version to appear in e-Publications@Marquette. Elsevier does not grant permission for this article to be further copied/distributed or hosted elsewhere without the express permission from Elsevier. 
NOT THE PUBLISHED VERSION; this is the author's final, peer-reviewed manuscript. The published version may be accessed by following the link in the citation at the bottom of the page.

40. Polich J, Pitzer A. P300 and Alzheimer's disease: oddball task difficulty and modality effects. Electroencephalogr Clin Neurophysiol Suppl. $1999 ; 50: 281-287$.

41. Polich J, Squire LR. P300 from amnesic patients with bilateral hippocampal lesions. Electroencephalogr Clin Neurophysiol. $1993 ; 86: 408-417$.

42. Ritter W, Vaughan HG., Jr Averaged evoked responses in vigilance and discrimination: a reassessment. Science. 1969;164:326-328.

43. Smith ME, Halgren E, Sokolik M, Baudena P, Musolino A, Liegeois-Chauvel C, Chauvel P. The intracranial topography of the P3 event-related potential elicited during auditory oddball. Electroencephalogr Clin Neurophysiol. 1990;76:235-248.

44. Strobel A, Debener S, Sorger B, Peters JC, Kranczioch C, Hoechstetter K, Engel AK, Brocke B, Goebel R. Novelty and target processing during an auditory novelty oddball: a simultaneous event-related potential and functional magnetic resonance imaging study. Neuroimage. 2008;40:869-883.

45. Tournoux JTaP. Co-Planar Stereotaxic Atlas of the Human Brain. Thieme Medical Publishers; New York: 1988.

46. Vanni S, Warnking J, Dojat M, Delon-Martin C, Bullier J, Segebarth C. Sequence of pattern onset responses in the human visual areas: an fMRI constrained VEP source analysis. Neuroimage. 2004;21:801-817.

47. Volpe U, Mucci A, Bucci P, Merlotti E, Galderisi S, Maj M. The cortical generators of P3a and P3b: a LORETA study. Brain Res Bull. $2007 ; 73: 220-230$.

48. Yang L, Liu Z, He B. EEG-fMRI reciprocal functional neuroimaging. Clin Neurophysiol. 2010;121:1240-1250.

Neurolmage, Vol. 60, No. 4 (May 2012): pg. 2247-2257. DOI. This article is @ Elsevier and permission has been granted for this version to appear in e-Publications@Marquette. Elsevier does not grant permission for this article to be further copied/distributed or hosted elsewhere without the express permission from Elsevier. 